Marquette University

e-Publications@Marquette

School of Dentistry Faculty Research and

Publications

Dentistry, School of

3-1-1994

\title{
Clinical Occupational Bloodborne Exposure in a Dental School
}

Cesar D. Gonzalez

Marquette University, cesar.gonzalez@marquette.edu

Ronald J. Pruhs

Marquette University

Elise Sampson

Marquette University

Published version. Journal of Dental Education, Vol. 58, No. 3 (March 1994): 217-220. Publisher link. (C) 1994 American Dental Education Association. Used with permission. 


\section{Clinical Occupational Bloodborne Exposure in a Dental School}

Cesar D. Gonzalez, D.D.S., M.S.; Ronald J. Pruhs, D.D.S., M.S.; Elise Sampson, L.D.S., R.C.S.

Drs. Gonzalez and Pruhs are in the Department of Developmental Sciences and Community Health, and Dr. Sampson is in the Department of Diagnostic Sciences all at Marquette University, School of Dentistry. Please send correspondence and reprint requests to: Cesar D. Gonzalez, D.D.S., MS., Department of Developmental Sciences and Community Health, Marquette University, School of Dentistry, 604 N. 16th Street, Miluaukee, WI 53202.

I n recent years, infection control procedures designed to minimize the risk of transmission of infection between health care workers (HCWs) and patients have received increased attention. Of particular concern to dental health care workers are the pathogens human immunodeficiency virus (HIV) and the hepatitis B virus (HBV). Both are bloodborne pathogens also found in saliva, and other body fluids. ${ }^{1-6}$

Because of the invasive nature of many dental procedures, the use of sharp instruments, and the potential for blood contact, particularly parenteral blood contact, dental providers, dental students, and staffare potentially at risk of becoming infected with a bloodborne pathogen such as HIV or HBV via an occupational exposure. A recent study of dentists at the health screening program of an American Dental Association annual session estimated the annual occupation related injury rate among these dentists to be 3.21 injuries per year. $^{7}$

Although similarities between modes of transmission of HIV and HBV have been recognized, the risk of acquiring $\mathrm{HBV}$ infection is greater. Following a percutaneous exposure to $\mathrm{HBV}$, the risk of acquiring the infection ranges from 6 percent to 30 percent ${ }^{8,9}$ while a percutaneous exposure to HIV results in a 0.36 percent risk of acquiring the infection. ${ }^{10}$

Few data exist regarding bloodborne occupational exposures among dental care providers in a dental school. The objective of this study is to describe the frequency, type, and distribution of clinical occupational exposures among dental stu- dents, dental hygiene students, dental staff, and faculty at Marquette University School of Dentistry in the academic years 1989-90, 1990-91, and 199192.

\section{MethoDS}

Exposure incidents at the dental school are reported to the Clinic Director and/or to the Infection Control Officer and an incident report is completed. Information for this study was taken from the exposure incident reports for the 1989-90, 1990-91, and 1991-92 academic years. Each incident report included the following information: type of worker exposed (e.g., dental student, dental hygiene student, etc.), gender, date of exposure, operatory site of exposure, type of exposure, health information of the patient involved, and exposed person medical follow-up. Additional openended information was solicited and documented on some of the reports; for example, when and how the exposure occurred.

For this report occupational exposures are defined by the Occupational Safety and Health Act (OSHA) standard, which is "skin, eye, mucous membrane, or parenteral contact with blood or other potentially infectious materials that may result from the performance of an employee's duties." ${ }^{11}$ Three types of exposures were recorded: percutaneous exposure (needlestick or other injury with sharp instrument), cutaneous exposure (prolonged skin contact with blood/body fluids or 
Table 1. Reported Occupational Exposures at Marquette University by Type of Worker, 1989-92 (Fisher's Exact Test at level P<0.05).

\begin{tabular}{|c|c|c|c|c|c|c|}
\hline \multirow[b]{3}{*}{ Type of Worker } & \multicolumn{6}{|c|}{ Academic Year } \\
\hline & & & 199 & & & \\
\hline & $\mathrm{n}^{*}$ (total) & $\% 5$ & $n^{*}$ (total) & $\%$ & $n^{*}$ (total) & $\%^{5}$ \\
\hline Dental Students (DS) & $4(263)^{* *}$ & 1.5 & $18(231)^{6 / 4}$ & 7.7 & $19(195)^{* *}$ & 9.7 \\
\hline Dental Hygiene Students (DHS) & & & $2(30)^{* *}$ & 6.6 & $1(36) * *$ & 2.7 \\
\hline Clinical Staff & $1(26)^{\#}$ & 3.8 & $2(23)^{\#}$ & 8.6 & $3(22)^{\#}$ & 13.6 \\
\hline Clinical Faculty & & & $1(256)^{\#}$ & 0.4 & & \\
\hline
\end{tabular}

- Number of reported exposures per group, per academic year.

-Total number of sophomores, juniors, and seniors enrolled in pre-clinical and clinical work (DS) and (DHS).

${ }^{5}$ Percent of reported exposures per group, per academic year.

Total number of clinical staff and clinical faculty (full- and part-time).

contact of broken skin with blood/body fluids), and mucous membrane or corneal exposure (splashes to mouth, eyes or other mucous membranes). Distributions were compared for significance using the Fisher's Exact Test at $<0.05$.

\section{RESULTS}

A total of 51 occupational exposures were reported to the Clinic Director or Infection Control Office during the period of the study. Five exposures were reported in the $89-90$ academic year. Occupational exposure reports increased significantly $(\mathrm{p}<0.05)$ with 23 exposure reports in each of the last two academic years of the study (1990-91 and 1991-92).

Dental students reported 41 occupational exposures ( 80 percent). Dental staff reported six exposures (12 percent). Dental hygiene students reported three exposures ( 6 percent) and faculty reported one exposure ( 2 percent) (Table 1$)$. Sophomore dental students reported one laboratory related exposure ( 2 percent). Junior dental students were responsible for most of the exposure reports with 23 ( 45 percent) while senior dental students reported 17 exposures ( 33 percent). The difference between the number of exposures reported by junior and senior dental students was not significant $(\mathrm{p}<0.05)$.

Of the 51 occupational exposures reported, 50 exposures ( 98 percent) were percutaneous injuries. Only one exposure ( 2 percent), a corneal injury, was not percutaneous. Of the 50 percutaneous injuries, needlesticks were the most common with 18 injuries reported ( 36 percent). Nine explorer injuries accounted for 18 percent of reports. Seven scaler injuries accounted for 14 percent. Seven laboratory related injuries also accounted for 14 percent. Four dental bur injuries accounted for 8 percent. Other instruments accounted for the remaining 10 percent including crown removers with two exposures and elevators, blades, and cavitron tips with one exposure each.

More than half of the occupational exposures
(28) occurred in restorative clinics (operative, fixed prosthodontics, removable prosthodontics, and endodontics). In these clinics, needles accounted for 13 exposures. Explorers accounted for six exposures, dental burs four exposures, scalers two exposures and other instruments (crown remover, cavitron tip) three exposures. Five exposures (10 percent) occurred in the periodontal clinic and three exposures ( 6 percent) occurred in the dental hygiene clinic. In these clinics scalers were the most common cause with five exposures. Needles accounted for two exposures and there was one corneal exposure. Seven exposures (14 percent) occurred in the laboratory. Five exposures (10 percent) occurred in oral surgery. Needles accounted for three exposures, explorers one ex. posure, and other instruments (elevator) one exposure. Two exposures ( 4 percent) occurred in the patient screening room and one exposure (2 percent) in the locker room.

\section{DisCUSSION}

In a retrospective analysis at Marquette University School of Dentistry, the frequency, type, and distribution of clinical bloodborne occupational exposures in three academic years were studied The number of reported exposures increased almost five times in the second academic year and stayed the same in the third. The authors believe the reason for the increased number of occupational exposure reports in the last two academic years was a result of increased awareness among dental students, faculty, and staff of the possible consequences of bloodborne disease exposures in their workplace and a better knowledge of the school's Infection Control Protocol.

A prior study involving practicing dentists reported that age, experience, and skill were not related to injury rate. ${ }^{7}$ The data from the present study support this finding since no significant difference was found in the number of exposure incident reports between juniors and seniors in the three years of the study. Comparison between stu- 
dent and faculty exposures was not possible because of limited faculty/patient contact.

The results of this study show that among dental students at Marquette University, needlestick injuries were the most common form of occupational exposure. This finding is different from a study performed at the University of 'Texas Health Science Center at San Antonio, Dental School ${ }^{12}$ where lacerations were the most common form of occupational exposure and needlestick injuries were second. A recent survey of dentist participants and non-participants in the health screening program at the American Dental Association's annual session (1987 through 1991), ${ }^{7}$ reported dental burs as the most common source of injury ( 37 percent), followed by syringe needles (30 percent). A retrospective analysis of occupational injuries at Bristol Dental Hospital between 1980 and 1988 found sharps injuries to be the most common type of occupational exposures with 55 percent of all recorded injuries. ${ }^{15}$

A study of 144 Scottish general practitioners who were questioned about the number of needlestick injuries received over a three-year period, reported 80 percent receiving at least a single injury. ${ }^{14}$ This compares with 60 percent of 543 Irish dentists ${ }^{15}$ and 71 percent of 325 Malaysian dentists ${ }^{16}$ who received such injuries within similar time spans. These findings are similar to studies of medical personnel. ${ }^{17 \cdot 20}$

Junior and senior dental students at Marquette University School of Dentistry spend approximately 80 percent of their clinical time performing restorative procedures. As a result, the majority of exposures occurred in restorative clinics. This result is similar to findings reported in a previous study of practicing dentists. ${ }^{7}$

The open-ended portion of the incident reports indicated that many of the needlestick exposures occurred because of improper needle recapping and disposal techniques. In addition, some injuries also occurred at clean-up time. Heavy duty gloves, required by the school's Infection Control Protocol were used only sporadically. The use of needle disposal units in clinic areas as well as information given to students and staff regarding correct ways to recap needles (e.g., scoop method) are preventive measures that were implemented and reinforced subsequent to this report. The effect of these preventive measures, implemented at the Marquette University School of Dentistry, is yet to be investigated. Some controversy exists concerning whether or not adherence to Universal Precautions (UPs) reduces the risk of occupational exposures. A few studies have reported that UPs alone are not sufficient to reduce the risk of needlestick or other sharps injuries. ${ }^{21,22}$ However, Wong et al, ${ }^{23}$ reported a 62 percent reduction in the frequency of needlestick injuries after the implementation of UPs. Other studies that have focused on the epidemiology of needlestick injuries suggest that placement of puncture-resistant needle disposal units at the site of use can prevent certain types of needlestick injuries, especially those due to recapping, transport of uncapped needles, and improper disposal techniques. ${ }^{24,25}$

The one occupational exposure that was not percutaneous is worth special notice. A student had removed his safety glasses and was exposed to a mixture of local anesthetic and aspirated blood by being squirted in the face when a faculty member placed the anesthetic syringe onto the bracket table after injecting the patient for the student.

This study serves to identify high risk clinical procedures and clinical areas for bloodborne occur pational exposures at a dental school. It underscores the frequency of risk encountered by students, staff, and faculty and emphasizes the need for increased diligence in seeking to reduce this risk.

\section{References}

1. Heathcote J, Cameron CH, Dane DJ. Hepatitis B antigen in saliva and semen. Lancet 1974;1:71-3.

2. Groopman JE, Salahuddin $S Z$, Sarngadharan MG, et al. HTLV-III in saliva of people with AIDS related complex and healthy homosexual men at risk for AIDS. Science 1984; 226:447-9.

3. Ho DD, Byington RE, Schooley RT, Flynn T, Rota TR, Hirsch MS. Infrequency of isolation of HTLV-III virus from saliva in AIDS. N Engl J Med 1985;313:1606.

4. Gallo RC, Salahuddin SZ, Popovic M, et al. Frequent detection and isolation of cytopathic retrovirus (HTLV-III) from patients with AIDS and at risk for AIDS. Science 1984;224:500-3.

5. Brodersen M, Stegmann S, Klein KH, Trulzccli D, Rensch P. Salivary HBAg detected by radioimmunoassay. Lancet 1974;1:675-6.

6. Villarejos VM, Visona KA, Gutierrez A, Rodriguez A. Role of saliva, urine, and feces in the transmission of type B hepatitis. N Engl J Med 1974;291:1375-8.

7. Slew C, Chang S, Gruininger SE, et al. Self-reported percutaneous injuries in dentists: Implications for HBV, HIV transmission risk. J Am Dent Assoc, 1992;123:37-44.

8. Seem LB, Wright EC, Zimmerman HJ, et al. Type B hepatitis after needlestick exposure: Prevention with hepatitis B immunoglobulin. Ann Intern Med 1978;88:285-93.

9. Grady GF, Lee VA, Prince AM, et al. Hepatitis B immunoglobulin for accidental exposures among medical personnel: Final report of a multicenter controlled trial. J Infect Dis 1978;138:625-38.

10. Tokars JI, Marcus R, Culver DH, et al. Survey of HIV infection and Zidovudine use among health care workers after occupational exposure to HIV-infected blood. Ann Int Med 1993;118:913-9.

11. Occupational exposure to bloodborne pathogens. Final Rule, 29 CFR part 1910.1030 Federal Register 1991;56:64175-82.

12. Cottone JA, Dillard RL, Dove SB. Frequency of percutaneous injuries in dental care providers. J Dent Educ 1992;56:34, \#14. 
13. Porter KM, Scully C, Porter S, Theyer Y. Needlestick injuries to dental staff. Br Dent J 1989;167:265-6.

14. Samaranayake LP, Lamey PJ, Mcfarlane TW, Glass GWJ. Attitudes of general dental practitioners towards the hepatitis B vaccine. Comm Dent Oral Epidemiol $1987 ; 15: 125.7$.

15. McCartan BE, Samaranayake LP. Awareness and acceptance of hepatitis $B$ vaccine by Irish dental practitioners. J Ir Dent Assoc 1987;33:33-6.

16. Yaacob HB, Samaranayake L.P. Awareness and acceptance of the hepatitis B vaccine by dental practitioners in Malaysia. J Oral Pathol Med $1989 ; 18: 236-9$.

17. Wormsen GP, Rabkin CS, Joline C. Frequency of nosocomial transmission of HIV infection among health care workers. N Engl J Med 1988;319:307-8.

18. Jagger J, Hunt EH, Brand-Elinaggan J, Pearson RD. Rates of needlestick injury caused by various devices in a university hospital. N Engl J Med 1988;319:284-8.

19. Marcus R, CDC Cooperative Needlestick Surveillance Group. Surveillance of health care workers exposed to blood from patients infected with the human immunodeficiency virus. N Engl J Med 1988;319:1118-23.
20. Tokars JI, Bell DM, Culver DH, et al. Percutaneous injuries during surgical procedures. JAMA $1992 ; 267: 2899-904$

21. Krasinski K, LaCouture R, Holzman RS. Effect of changing needle disposal systems on needle puncture injuries. Infect Control 1987;8:5962.

22. Linnemann CL, Cannon C, DeRonde M, Lanphear B. Effect on educational programs, rigid sharps containers, and universal precautions on reported needlestick injuries in health care workers. Infect Control Hosp Epidemiol 1991;12:214-9.

23. Wong ES, Stotka JL, Chinchill VM, Williams DS, Stuart GC, Markowitz SM. Are universal precautions effective in reducing the number of occupational exposures among health care workers? JAMA 1991;265:1123-8.

24. Ribner BS, Landry MN, Gholson GL, Linden LA. Impact of a rigid, puncture resistant container system upon needlestick injuries. Infect Control 1987;8:63-6.

25. Becker MH, Janz NK, Band J, Bartley J, Snyder P, Gaynes RP. Noncompliance with universal precautions policy: Why do physicians and nurses recap needles? Am J Infect Control 1990; 18:232-9. 